\title{
Combined with the Actual Situation of Students on the Practical Teaching Reform of Thinking and Politics Thinking
}

\author{
Lin $\mathrm{Xu}$
}

Jiangxi Vocational Techlege Of Industry \& Trade, Jiangxi, Nanchang, 330038

739960103@qq.com

\begin{abstract}
The ideological and political education course of colleges and universities is the main way to improve the ideological and political level of college students, in the course of thinking politics, students should not only learn systematic Marxist theory, establish a correct outlook on life, values, world view, but also learn how to make correct choices in practice using Marxist knowledge. In order to meet the needs of quality education, adapt to the training mode of college personnel, enhance the effectiveness of the teaching of thought and politics, cultivate cultural self-confidence, road self-confidence, institutional self-confidence, theoretical self-confidence, for the great rejuvenation of the Chinese nation's socialist successors, we must strengthen the practical teaching of thought and politics classes. This paper discusses the current situation of the university's thought and politics course, and puts forward some opinions on the reform of the practical teaching of the thought and politics course.
\end{abstract}

Keywords : Thought politics class, Practical teaching, Teaching reform

\section{结合学生的实际情况对思政实践教学改革的思考}

\author{
徐琳
}

\section{江西工业贸易职业技术学院 江西 南昌 330038 \\ 739960103@qq.com}

\section{摘要}

高校的思政教育课程是提升大学生思想政治水平的主要途径, 学生在思政课程之中, 不仅仅要学习到系统的马 克思主义理论, 树立正确的人生观、价值观、世界观, 还要学习到如何在实践之中利用马克思主义知识做出正 确选择。为了适应素质教育的需要, 契合高校人才培养模式, 增强思政课教学的实效性, 培养出文化自信、道 路自信、制度自信、理论自信，为中华民族伟大复兴不断努力的社会主义接班人，必须加强对思政课的实践教 学。本文就高校思政课现状进行讨论, 提出一些对思政课实践教学改革的意见。

关键词: 思政课; 实践教学; 教学改革

\section{1. 高校思政课现状}

\section{1. 思政教学观念陈旧, 忽视教学形式改革}

近年来, 随着经济全球化和社会主义市场经济的 不断发展, 社会上人们普遍存在重智育、轻德育, 重 科技、轻人文的思想观念, 许多高校对思政课教学的 重视度不高, 仅仅靠聘请来的教师在课堂之上进行思 政教育, 而不去顺应时代的发展, 对思政课进行改革。
有些高校虽按照教育部门的要求进行改革, 但只注重 思政课程内容的改革, 而不去对思政课教学方式进行 改革。高校中思政课教师一直采用的是传统的教学方 式, 在课堂之上靠着教师一个人的讲述来对学生灌输 知识, 整个课堂就像一个讲座, 学生只在教学过程中 扮演听众角色, 课堂氛围枯燥乏味, 让学生没有学习 的积极性。高校大学生在学习思政课理论知识时, 依 靠单纯的讲述不能对马克思主义进行理解, 也无法意 识到思政课理论学习的重要性。产生这一现象的主要 原因便是教师给学生带来的引导不够, 教师在教学中 
所持的教学观念比较老旧, 还是以应试教育的理念来 面对学生进行教学, 仅仅以提高学生成绩作为教学目 标, 对于国家教育部出台的对于高校加强素质教育的 要求不重视, 在长久的教学生涯中始终运用一套办法 教学学生, 对于教师来说, 这样的教育方式相对来说 比较轻松, 只要在开始教学的前期做好课程准备就行, 在课程中途也不会按照学生的现实情况进行课程的 调整, 这样的教学方式十分呆板, 思政课堂之上, 教 师也渐渐在讲台上唱起了 “独角戏”, 这样十年如一 日的教学方式没有顺应时代的发展, 没有对教学进行 改革, 也会渐渐被时代和学生所抛弃。

表 1: 教师对思政实践教学重要性认识

\begin{tabular}{|c|c|c|c|}
\hline $\begin{array}{c}\text { 教师对实践教 } \\
\text { 学重要性认识 }\end{array}$ & 非常重要 & 重要 & 不重要 \\
\hline 所占比例 & $93.24 \%$ & $5.83 \%$ & $0.93 \%$ \\
\hline
\end{tabular}

表 2: 教师对思政课实践教学效果的反映

\begin{tabular}{|c|c|c|c|}
\hline $\begin{array}{c}\text { 教师对实 } \\
\text { 践教学效 } \\
\text { 果反映 }\end{array}$ & $\begin{array}{c}\text { 有明显效 } \\
\text { 果 }\end{array}$ & $\begin{array}{c}\text { 稍微有效 } \\
\text { 果 }\end{array}$ & 没有效果 \\
\hline 所占比例 & $24.48 \%$ & $48.95 \%$ & $26.57 \%$ \\
\hline
\end{tabular}

\section{2. 实践教学对于思政课程来讲有一定难度}

高校思政课知识中包括了马克思列宁主义、毛泽 东思想、邓小平理论、“三个代表” 重要思想、科学 发展观以及习近平新时代中国特色社会主义思想等 基本理论知识, 理论知识的学习枯燥无味, 思想概念 也比较抽象, 这些特点都增强了学生的学习理解难度, 在一定程度上降低了学生的学习积极性, 教学也不会 有良好的效果。思政课理论知识内容也有些脱离学生 生活实际, 学生无法联系实际生活, 也就无法对思政 课理论知识进行很好的理解和利用, 学生会在内心产 生学习思政课知识无用的心情, 对思政课教学认识产 生偏差, 丧失学习的主观能动性, 失去了思政课教学 的意义。思政课程的教学实践有一定难度, 因为思政 课程中含有马克思主义发展历程、中国革命历史、爱 国主义教育等等重要内容, 这些内容以理论知识为主, 相对于其他课程来说其知识内容的实现是在学生的 内心形成马克思主义哲学理念, 学生对思政内容的学 习也以理解内涵为主, 相对来说实践教学的实现比较 困难, 教师需要对此进行深入的研究实践。

\section{3. 缺乏思政课实践教学场地}

高校的专业课程一般都会有专业的实践基地, 但 思政课往往没有相关的实践基地来让教师在思政课 上使用实践教学方式。学校对于思政课不够重视, 会 认为思政课实践教学没有必要, 并且许多高校都存在 着资金不足的问题, 高校由于培养技术型人才需要, 通常会将经费用于专业课程之上, 而不是建设思政实 践教学场地。在现实校园建设时, 学校在开展基地建
设时会遭遇种种困难，审批困难或者对思政课实践基 地设计的困难，都会让思政课实践教学基地很难有效 建立。思政课如果采用实践教学方式, 那么实践教学 基地的缺失会让思政课实践教学难以开展。同时学校 也难以同企业事业形成合作，因为相对于专业课程来 说, 思政课程实践无法给企业带来现实利益, 企业自 然就对此表示拒绝。教师在实践教学时由于这些种种 原因导致落实单位、商讨费用等步骤难以进行, 长此 以往, 教师实行实践教学的积极性被强烈打压, 学生 也会对思政课实践教学从好奇兴奋转为对实践课的 厌恶。长此以往学校难以保证思政课实践教学的实际 成效。

\section{4. 社会整体环境对学生认知造成影响}

在新中国刚刚成立时，因为当时政治形势的影响， 当时的大学生对思政课程比较重视, 思政教学水平也 比较高, 人们对于学习马克思主义的热情高涨, 社会 呈现出一阵兴兴向荣的朝气。而中国实行改革开放之 后, 社会主义市场经济的实行, 经济发展成为了社会 建设的主要目标, 学校之中也出现了对思政教育的忽 视, 学生对思政课的积极性也大大降低。社会逐渐变 得浮躁, 高校之中与推进经济发展的学科受到学生的 欢迎和学校的重视, 而忽略了思政课程的教学。并且 现今网络的发达使得许多学生获取信息的主要渠道 便是各个网络平台, 而由于网络发言的匿名性, 许多 人在网络上发表的不当言论也会被学生看到, 当今学 生面对繁杂的网络信息, 缺少内心坚定的信念, 便很 容易在这样的网络與论之下动摇自己的信仰, 最后影 响原本的认知。在中国特色社会主义蓬勃发展的时候, 国家更加需要培养热爱国家, 利用马克思主义理论实 现中华民族伟大复兴的人才。社会和学校需要开始重 视思政课教学, 培养学生的心理教育, 而不只是将经 济发展放在对学生教育的领头位置。企业在聘请人才 时也要注重员工的政治素养和综合素质, 带动学校提 升思政课教育的地位。

\section{2. 实践教学优势}

\section{1. 学习方面}

培养学生实践能力和操作能力的关键在于实践 教学, 实践教学还可以培养学生的观察力和思维能力。 在高校教学之中, 无论哪门课程都离不开实践教学。 实践教学便是让学生将理论知识运用在实际生活中 的能力, 从没有实践能力到有实践能力, 是知识转化 的从无到有的过程。在实践教学之中, 学生利用自己 学会的理论知识, 与实践操作紧密结合形成了实际的 操作能力, 学生只有拥有实际操作的能力, 才能在实 践之中发现缺点, 及时改进, 甚至对其创新, 形成新 的理论知识。认识到实践再到认识, 是马克思主义哲 学中的重要内容, 人的认识是在实践之下呈螺旋上升 的状态的, 如果缺失了实践这一过程, 那么人类的认 识就会停滞不前, 无法创新。思政课程中增加实践教 
学, 能够给学生带来最直接的冲击, 课本上晦澀难懂 的理论知识在现实的演示下变得清晰, 学生在实践教 学之中能够很好的理解思政知识中的难点。

\section{2. 育人方面}

教书的深层目的不是为了考试, 而是为了育人。 学生在努力学习课本知识以外, 还要主动接触实际, 到生活中实践, 认识到课本上所讲述的道德和精神在 生活中的体现, 坚定内心的信仰, 锻炼自己成为一个 德智体美劳全面发展的有用之才。比如学生的浪费现 象, 现在许多高校的学生都有浪费的习惯, 由于想要 瘦身等等原因, 在食堂中吃饭不将自己盘中的食物吃 完, 剩下的一大半倒掉, 毫无愧疚之心, 思政课教师 可以针对这一现象对学生进行教育, 不仅仅要在课堂 之上对学生讲述粮食的来之不易, 还可以通过带学生 去往田野之间, 体验粮食的种植、收割, 让学生在劳 动之中切切实实感受到粮食的珍贵, 从此以后便会对 粮食抱有一颗敬畏之心。这样的实践教学才是真正有 效的育人教育。

当今很多家长对孩子教育都是持着宠溺的态度, 许多学生因为家庭的教育, 始终没有学会自立自强。 教师要在实践教学之中培养学生发现问题、分析问题、 解决问题的能力, 提升学生的社会生存能力。教师要 进一步延伸课堂活动, 将教育从课堂延伸至课外的实 践教学, 发掘学生潜在的能力。理论和实践的结合可 以让学生在课程中学会自立自强, 将学生培养成为一 个优秀的社会主义接班人。

实践教学之中能够重现经典历史画面, 能够给学 生带来最直接的视觉冲击, 原本课本上描绘的历史人 物, 只有学生在实践教学中真实面对, 才能深入理解 先人的不易, 更加珍惜现在的生活, 铭记历史, 以史 为鉴，坚定心中的爱国信念。

\section{3. 将实践教学融入思政课的必要性}

习近平在会议上曾说过: ““大思政课” 我们要善 用之, 一定要跟现实结合起来。上思政课不能拿着文 件宣读, 没有生命、干巴巴的。” 高校教育必须与实 践相结合, 而不能光是教师在讲台之上拿着教材干巴 巴的进行宣读, 要把实践教学融入思政课程, 让思政 知识变得生动起来。马克思主义哲学告诉我们, 实践 是认识的源泉, 实践才能出真知, 实践是认识发展的 动力。只有在思政课上开展实践教学, 才能将课本上 的知识实实在在的展现在学生的眼前, 学生才能通过 实践提升自己的认识，从而提升自己的能力。自 2006 年开始, 高校思政课新课程设置过程中就被要求加强 课堂实践教学, 随着近几年改革开放的不断深入, 社 会上对人才的需求量越来越大, 高校的教育理念也在 外国文化的冲击之下慢慢发生改变, 中国的高校教育, 既要尊重传统, 也要与国际接轨, 为国家与社会培养 实践性人才, 在这样的要求之下, 思政课也要跟随时 代的发展而改进, 高校之中也要对思政课进行实践教
学。思政课缺失了实践教学, 思政知识便会成为课堂 之上的一句空话, 导致政治理论知识与学生的生活实 践严重脱节。学生在课堂之上感受到的只是老师喋喋 不休的空话和大道理, 与现实生活的不搭界, 也会使 学生会思政教育缺失兴趣。现如今我国大学思政教育 使我们必须寻求思想政治学科理论与实践运用的契 合点, 重视和加强对思政课征的实践性教育模式和教 育途径的探索。

实践教学改革是提高高校思政教育时效性的基 础。大学思政课程内容较多, 理论性较强, 但靠教师 在课堂之上的讲述是很难让学生对所有内容进行理 解的, 而思政教学就能够提高思政教学的效率, 提高 思政知识对学生的说服力, 引起学生对思政课程的共 鸣, 提高学生对思政课程的积极性, 使学生都能够积 极参与到思政教学之中, 这样自然而然教师在课堂上 详细讲述的时间就变少了, 教学质量也得到了提高。

同时思政课程中加入实践教学时教育现代化的 必然要求, 教育现代化便是要求学校的教育方式在统 一的前提之下还要具备多样性, 丰富教学中的活动。 教学必须要跟随着时代的发展不断进步, 注重学生的 实际需要, 在这样的时代前提之下, 思政实践教学变 成了高校发展中的必然因素。

\section{4. 思政课实践教学改革方式}

\section{1. 创新教育理念}

思政课传统的教育方式是教师在课堂之上，对着 学生进行灌输式的教学, 将学生作为课堂的听众, 而 将教师作为课程的主导者, 这种教育理念严重束缚着 学生的个性和创造性, 使学生的能力没有发挥的地方, 这种偪化的教育方式就让课堂成为了一个死气沉沉 的地方。教师在教育过程当中应该转变传统的教育理 念, 创新教学方式, 在课堂之上, 把以教师为主转变 为以学生为主, 结合学生的实际情况及教学需求, 及 时调整教学进程。在教学过程中, 教师可以使用探索 启发式教学、自主讨论式教学等等方式, 让学生真正 参与到课堂教学之中, 使得教师在课堂之上的身份从 传统的主导者、领导者转化为引导者和帮助者, 引导 学生在课堂上的思维扩散, 在其中及时纠正学生的错 误观念, 潜移默化的转变着学生的思维方式, 激发着 学生在课堂之上的主动性与积极性。教师通过创新教 育理念, 可以增强课堂之上师生的互动, 使课堂的氛 围变得活跃, 提升师生之间的沟通效率, 让学生通过 老师对老师的兴趣, 增加对思政课程的顺序, 从而提 升思政课堂的教学效率。

\section{2. 提升教师团队素质}

习近平总书记曾在会议中强调: “要遵循思想政 治工作规律, 遵守教书育人规律, 遵循学生成长规律, 不断提高工作能力和水平。” 教师在思政实践教学之 中发挥着最重要的教育作用, 教师要坚持不断的学习, 
培养自己的思想政治素养, 才能在课堂之上对学生进 行优秀高效率的教学。学校要坚持对思政教师团队的 培养, 组织思政教师一同去往有着优秀思政教育的学 校进行沟通、交流和学习, 互相学习彼此的长处, 取 长补短才能使高校的思政教育氛围变得越来越好。高 校也要及时对违反师德、没有政治素养的教师进行剔 除, 不要让一位教师带坏了校园的风气, 维护校园内 的思政教育氛围, 使得学生能够获得最好的思政教学 体验, 提升思政教学质量。

\section{3. 加强实践教学基地建设}

实践教学基地是思政课实践教学的物质基础。实 践教学基地的建设是思政课社会大课堂的 “活教材”, 可以让大学生增长认识。学校可以让教师带领着学生 去往实践基地, 不同的实践基地可以对应着思政课本 的不同主题, 比如爱国主义教育基地, 革命传统教育 基地等等, 学生可以通过讲解和眼前看到的历史事实, 加深对思政课本上知识的认识。

政府可以带头某一地区的思政实践基地建设,让 同一地区的许多高校共享实践教学基地资源, 避免浪 费。政府带头的实践教学基地也会更加具有权威性, 同时, 实践教学基地也可以对外开放, 提供给市民参 观学习, 让思政课实践教学不仅仅面对高校大学生, 让爱国教育深入人民内心, 让孩子从小接受思政教育, 培养优良作风。在进行实践教学基地建设时, 要挖掘 当地的文化教育资源, 对当地的历史进行深层探究, 开展紧贴群众生活的社会服务活动, 让学生在社会服 务和实践中感受到思政课实践教学的魅力。

同时高校也要在校园建设中增加思政元素, 利用 图片、视频、音乐资源, 在学校内建设红色主题的实 践教学基地, 例如在学校长廊之上张贴中国革命英雄 人物的海报, 介绍他们的英勇事迹, 在课间时间播放 大家耳熟能详的红歌, 吸引学生的注意力, 在走廊上 放置电视或投影仪, 在固定时间播放革命电影, 激发 学生的学习和爱国热情, 利用真实的文化信息来带动 学生学习思政知识, 实现文化育人目标。

\section{4. 多渠道多途径开展思政实践教学}

高校要充分利用校内和校外的资源开展实践教 学, 在校园内, 学校可以开展多种多样的活动, 比如 结合思政知识举办辩论赛、讨论会、电影观摩等等活 动吸引学生参加、学习。这些有趣的活动, 能够提高 学生参与思政教学的积极性, 吸引学生的注意, 在参 加活动之中, 通过有趣生动的方式, 不知不觉就能学 习到思政知识, 提升思政教学实践与理论的结合。学 校还可以与博物馆、纪念馆或者社会服务活动联系, 开展参观、访问、志愿服务等活动, 拓宽思政实践教 学渠道, 对实践教学方法进行创新。通过多渠道多途 径开展思政实践教学, 能够让学生在生活与学习的方 方面面都能学习到思政知识, 并且是通过轻松愉悦的 方式所获得的, 提升了课堂上思政教学的效率。
高校要开展假期社会实践活动, 锻炼学生解决问 题的能力, 检验学生的思想道德品质。学校安排此种 实践活动, 要将其贴合思政课程内容, 符合学生的实 际情况。此种暑假、寒假的社会实践活动, 可以增强 学生体验社会, 参加劳动的主动性和积极性, 增强学 生责任意识。

\section{结论:}

思政课程使用实践教学方式进行思政教育, 是历 史发展的必然结果。实践教学是高校培养高素质人才 的重要一环, 进一步加强思政课实践教学建设工作是 目前高校必须重视的问题。思政实践教学要顺应时代 发展, 进行深入的创新与改革, 有效促进思政教育的 高质量、高效率发展。

\section{REFERENCES}

[1] ma fuyun, Hou yanna. deep integration of ":four in one" three-dimensional practical teaching mode [J]. Henan social sciences, 2020,28(05):118-124.

[2] Shuishuijiang, Gao Shunqi, Yin Jiade. On the "transformation and upgrading" of practical teaching of ideological and political theory courses in higher vocational colleges [J]. China Vocational and Technical Education, 2020(01):51-55.

[3] Tao Yufang. Thoughts on Integration - Some thoughts on how to integrate ideological and political education elements into practical teaching of professional courses in higher vocational colleges under the concept of "ideological and political courses" [J]. Education and Teaching Forum, 2019(52):50-51.

[4] Chen Yuan, Huang Zhenxuan. Analysis of the mode of "four modernizations combined" in practical teaching of ideological and political theory courses in higher vocational colleges [J]. Education and Occupation, 2019(02):84-87.

[5] Liu Jianping, Song Xia, Yang Zhi, Wang Zhaolun, Wang Shun. "Integration of production and education, school-enterprise cooperation" to build a practical teaching system in colleges and universities $[\mathrm{J}]$. research and exploration in laboratory, 2019,38(04):230-232+245.

[6] Chen Kun, Yin Shasha. Red Culture: Strategic Choice of Practical Teaching of Ideological and Political Theory Course in Colleges and Universities [J]. Guide of Ideological and Theoretical Education, 2017(04):104-107. 